\title{
NARRADOR, AUTOR, SUPERESTRELLA: \\ La narrativa latinoamericana en la época de cultura de masas
}

\author{
Por \\ JEAN FRANCO \\ Stanford University
}

La novela latinoamericana del boom (es decir, de finales de los años cincuenta y comienzo de los sesenta), en tanto que enaltece la idea del autor como "fundador" o "creador" de un universo texto original, lo antepone a otras dos figuras paradigmáticas: la del cuentista/narrador, cuya destreza se deriva de una cultura oral, y la del superestrella generada por !a producción de una cultura de masas. Estas tres figuras-narrador, autor, superestrella - corresponden a tecnologías radicalmente distintas de la narrativa, las cuales se relacionan con las funciones de la memoria, la historia y la repetición como modos de inscribir la vida social e individual. No se trata aquí, sin embargo, de categorías ideales. La singularidad del desarrollo desigual de América Latina ha permitido la persistencia de una cultura oral en áreas rurales y barrios de población marginal en las ciudades; ha mantenido por siglos una serie de limitaciones estructurales relativas a la alfabetización y al desarrollo de una cultura de imprenta (print culture); y, en la actualidad, ha tratado de facilitar la integración de la población latinoamericana al proceso de "modernización" capitalista a través de los medios de comunicación masiva, especialmente el cine, la radio, la televisión y las fotonovelas. Fue precisamente la rapidez de este salto de una tradición colectiva aprendida por la transmisión oral a la experiencia serializada de los mass media, junto con la persistencia del dinamismo de esta cultura oral y la producción de una literatura escrita elaborada como forma de resistencia cultural, lo que explica la interacción entre memoria, historia y repetición que propongo estudiar en algunas novelas del boom. ${ }^{1}$ Quiero demostrar además, que las figuras del narrador, autor y superestrella sirven como alegorías de formas de construcción social.

De estas figuras, el narrador pertenece a los estratos mas arcaicos de la cultura; evoca una época cuando el poder era ejercido a través de la palabra. Como historiador extraoficial de una cultura predominantemente

1. Para la relación entre formas de tecnología narrativa y formación sociales véase, Jean Franco, "La literatura, la crítica literaria y la teoría de la dependencia", Siempre, no. 720 de noviembre de 1975. 
oral/auditiva, el narrador o cantor de cuentos deriva su función y autoridad de saber las tradiciones, de su destreza inventiva en contar éstas dentro de formas rituales, y de la cercana coordinación entre la memoria individual del narrador y la memoria colectiva de los oyentes. ${ }^{2}$ No es simplemente, como Walter Benjamin sugirió, que "el narrador toma el material que cuenta de la experiencia- de su experiencia o de la experiencia narrada por otros--, y, en su lugar, hace de ella la experiencia de los que oyen su narración". Además, la historia narrada sirve para reproducir los valores comunales del grupo y enseñar ciertas formas de conducta social. ${ }^{3}$ Por esto, una cultura oral es a la vez fuertemente conservadora y (mientras persista la comunidad) fuertemente resistente a cualquier tipo de escritura. Depende del desarrollo de la memoria y del contacto directo entre las generaciones. El aviso de Platón de que la escritura atrofia la memoria y que sólo sirve para recordar hechos, encuentra su confirmación en la historia de Macondo: cuando por causa del insomnio se pierde la memoria, es la escritura la que la reemplaza. En América Latina, la cultura oral estuvo al margen de los cánones de la cultura dominante durante la época colonial; en el siglo XIX y comienzos del XX - época del liberalismo - fue considerada como signo de Barbarie; en las novelas de la tierra de los años veinte, treinta y cuarenta de nuestra época fue recuperada como un elemento de lo folklórico y popular, y por lo tanto como índice de lo auténtico.

Con el desarrollo de una cultura de imprenta la memoria colectiva y la memoria individual se separan. La historia escrita ahora registra los hechos acontecidos, haciendo de la memoria individual algo puramente idiosincrático y ajeno a la posteridad. Pero la cultura oral sobrevive gracias a su autoridad geneológica y su función ritual, en particular en el seno de las clases bajas y de los grupos o razas marginadas, proveyéndoles lazos frágiles con el pasado. La literatura escrita, sin embargo, comienza a dividirse de la historia; ambos toman funciones distintas, pues como observa Sansón Carrasco en el Quijote (parafraseando a Aristóteles): "es una cosa escribir como poeta y otra como historiador: el poeta puede decir o cantar cosas no como sucedieron pero como debieron haber sucedido, mientras que el historiador tiene que escribirlas no como debieron haber sucedido sino como sucedieron, sin añadir o quitar nada de la verdad". La imprenta ofrece un nuevo tipo de inmortalidad, tanto al narrador como a los personajes que va narrando. Así Shakespeare promete, por ejemplo, que:

2. Para un estudio sobre el uso de la memoria en culturas auro-orales véase a Walter Ong, The Presence of the Word (Yale University Press, 1967).

3. Walter Benjamin, "The Storyteller", Illuminations, (London: Jonathan Cape, 1970), pp. 83109. 
His beauty shall in these black lines be seen

And they shall live, and he in them still green.

Para los países dependientes y colonizados del mundo, esta separación entre historia y literatura ha de tener grandes consecuencias, ya que la historia constituye lo que Foucault ha llamado "un discurso de poder", cuyas reglas para excluir y seleccionar están organizadas por la metrópolis como medio de establecer y mantener su hegemonía cultural. Así a los latinoamericanos les fue asignado el papel de hijos que nunca madurarían, por los filósofos de la Ilustración, o de bárbaros, por el historicismo liberal del siglo XIX; y su continente como tierra del futuro fue relegado al silencio por Hegel. No exageramos al decir que mucha de la literatura latinoamericana fue generada por este problema de anacronismo-el sentido de exclusión o marginación de la "Historia". Un problema, además, que se agudizó, ya que por un lado la emancipación intelectual y el poder de generar un discurso nacional propio era esencial a la lucha por la liberación, pero por otro lado los intelectuales latinoamericanos hasta hace poco tenían que "pensar lo que otros habían hecho". Así es que para 1967 Carlos Fuentes, en su ensayo La nueva novela hispanoamericana, todavía habla de una brecha entre las aspiraciones universales del escritor y una realidad nacional que ofrece "como actualidades los temas ya tratados por Balzac, Zola, Tolstoi, Howells o Dreiser... [exponiendo] al escritor a un provincianismo de fondo y a un anacronismo de forma". ${ }^{4} \mathrm{O}$, más recientemente José Revueltas, en su cuento "Hegel y yo", confronta a Hegel (en el personaje de un estudiante cojo)-"Hegel con toda su filosofía de la historia y su Espíritu Absoluto... “-con un miembro del lumpenproletariado latinoamericano en quien el Espíritu Absoluto nunca estuvo: “... forrado de piel, una piel de cochino bien curtida, reluciente, olorosa". 5

No nos sorprende, entonces, que la noción del autor como héroe cultural (entre otros lugares en el ensayo del mismo Fuentes) viene a ser vista como una especie de salvación del anacronismo. No me refiero solamente al concepto restringido del autor dada por Foucault cuando habla de "la persona a quien se le puede atribuir legítimamente la producción de un texto, libro u obra", ${ }^{6}$ sino también a la noción del autor como inciador o fundador de un nuevo "cosmos" o "estado" dotado con la posibilidad de generar su propio discurso. Quiero sugerir que en la novela del boom se duplica el concepto del autor, ya que no sólo designa al escritor de una novela, sino a la novela misma funcionando como modelo sobre el cual se

4. La nueva novela hispanoamericana, (México: Joaquín Mortiz, 1969), p. 23.

5. Incluido en Material de sueños (México: Era, 1974).

6. Véase, "The Author", Language, Countermemory, Practice (Oxford, 1977). 
refleja el proyecto utópico de la formación de una nueva sociedad en los márgenes de la vieja.

Dependiendo de la creación literaria original y del poder creativo individual, este concepto del autor confronta durante la década de los sesenta un tipo distinto de tecnología narrativa-la cultura de masas elaborada para integrar al pueblo dentro de una sociedad orientada hacia la industrialización y el consumismo. La producción de esta cultura de masas se diferencia tanto de la cultura escrita como de la oral. Se basa en una forma de producción en serie en que $e l$ autor o autores y su posibilidad de originalidad formal ya no tienen importancia. Los productos de la cultura de masas obedecen al principio de repetición mecánica; sólo hace falta una pequeña variación en su contenido para que aparezcan como algo nuevo. Esto explica porque el sistema de "estrellas" (o por lo menos de los actores de telenovela o fotonovela) cobra tanta importancia: constituye lo que es "memorable". Daniel Boorstein señala en su libro The Image:

What the entertainment trade sells is not a talent, but a name. The quest for celebrity, the pressure for well-knowness, everywhere makes the worker overshadow the work. And in some cases, if what there is to become wellknown is attractive enough, there need be no work at all. For example, the Gabor sisters in the fifties became "film personalities" even though they had made almost no film at all. How thoroughly appropriate too that one of them should have become the 'author' of a bestselling "book".7

Pero hay otra razón para la importancia de la estrella en una cultura de masas, y es la aparente unificación que ofrece de una sociedad que cada día se hace más serializada y atomizada:

The agent of the spectacle, put on stage as a star, is the opposite of the individual; he is the enemy of the individual in himself as obviously as in others. Passing into the spectacle as a model for identification, the agent has renounced all autonomous qualities in order to identify himself with the general law of obedience to the course of things. ${ }^{8}$

En el momento más alto de su desarrollo, la novela latinoamericana impacta contra una cultura pop internacional que llamaba la atención de la juventud como fuerza de liberación ante la opresión de la familia y la cultura tradicional. Ya algunas formas de esta cultura, como el cine y la novela policiaca, habían fascinado a Borges (en cuyas ficciones juega un papel central la figuración de la repetición) y otros intelectuales del vanguardismo latinoamericano. Ninguno de los novelistas del boom ha podido evitar su influencia. García Marquez, Roa Bastos, Vargas Llosa, Cabrera Infante, Fuentes-todos escribieron guiones de cine quizás sin

7. Daniel J. Boorstin, The Image. A Guide to Pseudo-Events in America, (New York, Atheneum, 1973), p. 168.

8. Guy Debord, Society of the Spectacle (Detroit: Black and Red, 1970), p. 61. 
entender que auteur y autor no son la misma cosa. Fuentes dedica su novela Cambio de piel a Shirley McLaine y la intercala con fotos de artistas del cine; Manuel Puig parodia la literatura popular y el cine; Cabrera Infante y Luis Rafael Sánchez parodían canciones y espectáculos populares; en La tía Julia y el escribidor Vargas Llosa parodia la radio o la telenovela; Cortazar se adueña de Fantomas y los comics.

Paso ahora a considerar con más detalle este juego entre narrador/autor (como patriarca fundador)/estrella y memoria/historia/repetición en las novelas del boom. 9

\section{DEL NARRADOR AL AUTOR}

Cuando Don Segundo Sombra se aleja en su caballo del gaucho, representa simbólicamente el paso de un aprendizaje basado en la experiencia directa y la transmisión oral a un sistema de conocimiento basado en el libro y la lectura. Es interesante medir la distancia entre la síntesis ideal que ofrece Güiraldes de la oposición experiencia/libro y una alegoría de los años sesenta--"Los funerales de la Mamá Grande" de García Marquéz - en donde el mundo en desaparición de la cultura oral sólo puede ser representado en términos de lo maravilloso y lo grotesco. El cronista que emprende contar los funerales (antes de que los historiadores se adueñan del tema) se dedica al trabajo de rescatar solamente lo que él sabe que su público quiere recordar: nada de motivos o de discursos, sólo el esplendor del espectáculo. No le importa la exactitud descriptiva; su preocupación más bien es testimoniar el esplendor y la importancia de la ocasión y enumerar a los participantes, no tanto como individuos sino como tipificaciones de esta cultura ("la reina de la ahuyama verde, la reina del guineo manzano, la reina de la yuca harinosa", etc.). Lo que muere con la Mamá Grande, sin embargo, no es simplemente una cultura sino una forma de poder-el poder que emana del cuerpo y por extensión del territorio de la persona suprema, el poder matriarcal. Lo que reemplaza a la Mamá Grande es el poder abstracto, menos inmediato, de un presidente: "calvo y rechoncho, el anciano y enfermo presidente de la república desfiló frente a los ojos atónitos de las muchedumbres que lo habían investido sin

9. Este trabajo es parte de un estudio más extenso publicado bajo varios títulos, tales como "Ideología dominante y literatura: el caso de México posrevolucionario", en Carlos Blanco et. al., Cultura y dependencia (Guadalajara, Bellas Artes, 1976); "The Limits of the Liberal Imagination", Punto de contacto I, dic. 1975; "Conversations and Confessions. Self and Character in The Fall and Conversation in The Cathedral", Texas Studies in Literature and Language, vol. XIX no. 4, Winter 1977; "The Crisis of the Liberal Imagination and the Utopia of Writing”, Ideologies and Literature I (Minnesota, Dec. 1976-Jan. 1977). 
conocerlo y que sólo ahora podían dar un testimonio verídico de su existencia". Lo que el cronista quiere registrar no es la figura remota e insignificante de este presidente, sino lo que desaparece con su llegada: un mundo carnavalesco dedicado a la producción de lo inútil, lo grotesco y lo maravilloso, un rnundo que tiene que ser rescatado y registrado antes de ser relegado al olvido por un "discurso del método" generado por el nuevo sistema de poder abstracto, universal. Esta valoración de lo que no tiene ni valor de uso, ni valor de cambio, caracteriza también a la economía sobre la cual el discurso de Cien años de soledad se funda. Macondo es una sociedad surgida de la negación de la ética capitalista del trabajo y del estímulo al libre juego de las facultades e idiosincracias humanas fuera del reino del trabajo alienante. La separación de juego y trabajo corresponde a una separación de los principios de placer y realidad, de lo imaginario y lo real. Sin embargo, ya que Macondo es una utopía del juego y no de praxis épica, no puede representar la apoteosis de la historia, la cual, en todo caso, se está escribiendo en otro lugar. Por lo tanto, sus vidas pasan sin ser registradas por "la historia", excepto en un texto cerrado en sí que se encuentra también fuera del sistema de valores de uso o de cambio. Macondo viene a ocupar así un espacio ideal en donde las virtudes individuales de heroismo o atrevimiento intelectual florecen virtualmente sin las limitaciones impuestas por el estado burgués o las contaminaciones de una instrumentalidad económica. Cien años de soledad representa a la vez el proceso de fundación de una nueva sociedad desconocida por la cultura occidental, su pathos y su imposibilidad última. Los límites de Macondo trazan una alegoría social, significando que las energías frustradas en la realidad latinoamericana pueden ser liberadas en la ficción. La ficción crea el espacio mágico donde se pueden quebrar todos los tabúes sobre los cuales se funda la sociedad. Sin embargo, es una ficción extraña. En la misma forma en que la alquimia fundía ciencia y religión, teoría y práctica, antes de su separación en la época moderna, Cien años busca en su estrategia narrativa reencontrar la perspectiva del cronista oral para quien las cosas como son y como pueden o deben ser no son todavía distintas. Por lo tanto, lo anacrónico adquiere un signo positivo en la novela, ya que es la manera de generar la utopía en que se puede desplegar la singularidad de América.

Esta analogía entre padre fundador (de Macondo) y autor (de Cien años) tiene otra dimensión. La historia de Macondo no es sólo algo contado; también es una crónica escrita, anteponiendo al cronista entre las figuras del narrador de la cultura oral y el autor de la cultura del libro. Melquiades vive aparte de la familia pero comparte su vida. Actúa como la memoria de los Buendía. Pero el momento en que su crónica puede ser leída y descifrada por un lector es también el momento en que se crea una nueva 
relación y se destruye el mismo proceso de valoración de lo anacrónico en que se basa la novela. Detrás del cronista aparece el autor. ${ }^{10}$

\section{EL AUTOR Y EL FUNDADOR}

En su apogeo, la novela europea aspiraba a ser la historia del individuo en la sociedad. En contraste, la novela latinoamericana del boom presenta al héroe como un inventor o fundador al margen de la sociedad o fuera de ella. En Juntacadáveres y El astillero de Onetti, La casa verde de Vargas Llosa, Los pasos perdidos de Carpentier, Cien años de soledad de García Marquéz, La muerte de Artemio Cruz de Carlos Fuentes, y en ciertas alusiones y secciones de Rayuela se puede descubrir el topos narrativo común de la fundación de una sociedad (aunque sea sólo El Club de Serpientes en Rayuela) sin precedente, fuera del sistema de cambio, jerarquía y poder que condenó a las sociedades latinoamericanas al anacronismo y a la dependencia. Para precisar este topos mejor, miremos el caso de la isla de Fushía en La casa verde y algunos aspectos de novelas de Onetti y Fuentes.

Los episodios de la isla de Fushía en La casa verde están entrelazados con otros y enmarcados dentro del viaje en barco hacia la colonia de leprosos donde Fushía terminará sus días. El despliegue narrativo/temporal de estos episodios ha sido ya comentado por muchos críticos; quiero considerar aquí solamente su significación alegórica como momento de fundación. Al componer su novela de fragmentos acrónicos en que el presente narrado constantemente dialoga con o comenta el pasado, Vargas Llosa puede iluminar el surgimiento y la caida de Fushía a través de una irónica presciencia del lector. Y no sólo presciencia: la isla de Fushía alude también a una serie de preconceptos literario-culturales, en especial la isla de Robinson y la utopia misma como isla. La isla de Robinson es un modelo distorsionado de la producción europea, (Robinson se suple de herramientas obtenidas del naufragio); la isla de Fushía representa un modelo distorsionado de la economía latinoamericana, ya que Fushia no puede adentrarse en el sistema de intercambio "legítimo" organizado por Julio Reátegui y se ve obligado a robar a las comunidades indígenas. Es decir, Fushía es un pirata y parásito y no un empresario en el sentido capitalista.

La isla de Fushía es a la vez diabólica y bendita. Se nos presenta como un paraiso terrenal lleno de pájaros y ganado, cercado sin embargo por siniestros árboles lupuna que la marcan como lugar tabú para los indios.

10. Josefina Ludmer, Cien años de soledad: una interpretación (Euenos Aires: Editorial Tiempo Contemporáneo, 1972). 
La transición entre el estado de naturaleza y el estado de cultura se desarrolla en horas. Fushía quema la maleza, mata los pájaros y provee a los indios y 'cristianos' del lugar su primera comida cocida:

El fuego iba limpiando la isla y despoblándole: de entre la humareda salían bandadas de pájaros y en las orillas aparecían maquispas, frailecillos, shimbillos, pelejos que chillando saltaban a los troncos y ramas flotantes: los huambisas entraban al agua, los cogian a montones, les abrían la cabeza a machetazos y el banquete se están dando, Lalita, ya se les pasó la furia y ella yo también quiero comer, aunque sea carne de mono, tengo hambre.

Los tabúes de las lupunas y de la comida desaparecen al instante. Con la destrucción de la naturaleza y la "invención" de comida cocida se establece una nueva comunidad. La isla de pájaros toma los primeros pasos hacia la colonización humana. La aparición del paucar-pájaro que significa la sociabilidad-marca el próximo paso en este proceso: la construcción de la casa. La rapidez vertiginosa con que la isla de Fushía nace y cae se puede contrastar directamente con la empresa robinsoniana. Robinson se esfuerza para mantener un cuidadoso informe del tiempo; sabe cómo sublimar el deseo de satisfacción inmediata, invirtiendo su trabajo en actividades que darán beneficios futuros. Lo que Defoe llama "his indefatigable pains and industry" se calcula en meses y años. Robinson nombra Friday (viernes) a su esclavo, manteniéndose así en perfecta sincronía con la estructura metropolitana del tiempo. Si Robinson busca "sincronizarse" con la metrópolis, Fushía, por contraste, es un ser impaciente, anclado a la inmediatez. No puede fundar una comunidad permanente. Su isla es un punto de transición, un paso hacia el futuro. No tiene en sí un valor o una permanencia para él, como tampoco lo tiene el trabajo productivo (Fushía piensa que el esfuerzo de los huambisas en sembrar yuca es "pura mierda"). El valor se determina no por el trabajo invertido sino por el cambio: Lalita, su amante blanca, tiene valor, las "chunchas" no; el caucho tiene valor (es intercambiable), la yuca no. Así, esta fundación de una sociedad al margen o fuera del sistema resulta sin embargo sujeta al fin a la lógica de valores de cambio impuesta por el sistema.

Dentro de la estructura de la novela, la narración de la caída de la isla de Fushía sigue directamente a la descripción de su fundación, y la narración de su degeneración precede al episodio en que Fushía descubre la isla. Cuando Fushía abandona la isla para viajar a la colonia de leprosos, el proceso de transición repentina entre naturaleza y cultura aparece en inversión. Dentro de pocas semanas:

Sólo encontraron residuos de objetos herrumbosos, convertidos en aposentos de arañas y las maderas apolilladas minadas por las termitas. Salieron de las cabañas, recorrieron la isla y aquí y allá se inclinaban sobre leños carbonizados, latas oxidadas, añicos de cántaros. 
Los arboles crecen, devoran y aprisionan la isla nuevamente en un proceso parcialmente análogo al proceso de colonización.

Fushía, como fundador, se encuentra en un extremo opuesto al empresario capitalista primitivo representado por Robinson. Más que productor es consumidor; su necesidad de satisfacción inmediata representa un sacrificio de la posibilidad de permanencia. Su capacidad aminora con su virilidad. Tampoco puede organizar una verdadera comunidad de los vestigios marginales de la sociedad que reúne su isla: los indios drogados de la sierra, Lalita, un desertor, los huambisas. Con excepción de estos últimos, son seres que volverán poco a poco a una sociedad en la cual la vida y la memoria colectiva han desaparecido. La lepra de Fushía y la caída de su colonia son castigos morales impuestos por el autor a un personaje que representa el deseo de la burguesía sin su capacidad de sublimación, fuente de su capacidad productora y explotadora.

Este cierre "natural" que oculta un mensaje ideológico es común en la narrativa del boom. La situación de Fushía en La casa verde encuentra paralelos en el fracaso (político-moral) de Artemio Cruz. En la empresa final de El astillero, Larsen se ve obligado a canibalizar lo que fue un negocio próspero y a observar la reversión del astillero al estado de naturaleza. Mira herramientas "atravesados por los tallos rencorosos de las ortigas"; piensa en la naturaleza como algo motivado y dirigido hacia la destrucción de lo humano, simbolizado por estas herramientas que recuerdan los propósitos humanos para los cuales fueron inventados. En contraste al pasivo, derrumbado y abandonado paisaje industrial, la naturaleza aparece llena de energía. En su recorrido del astillero, Larsen encuentra un salvavidas cuya madera es "impudrible", aunque se ha podrido su cubierta de caucho manufacturado. Por todas partes es testigo de una batalla desigual: "las costras de orín, toneladas de hierro, la ceguera de los yuyos creciendo y enredándose". En ambas versiones de su fin, las últimas impresiones de Larsen son del secreto crecimiento del musgo, de la continuidad implacable de una forma de vida en que lo humano está fuera de lugar:

1) Sorda al estrépito de la embarcación, su colgante oreja pudo discernir aun el susurro del musgo creciendo en los montones de ladrillos y él del orín devorando el hierro.

2) Pudo imaginar en detalle la destrucción del edificio del astillero, escuchar el siseo de la ruina y del abatimiento. Pero lo más difícil de sufrir debe haber sido el inconfundible aire caprichoso de setiembre, el primer adelgazado olor de la primavera que se deslizaba incontenible por las fisuras del invierno decrépito. 
Frederic Jameson ha llamado "strategies of containment" (estrategias de contención) aquellos momentos en que la dinámica interna de una novela realista no puede ser en su totalidad adecuadamente incorporado en la narración. El dilema del rito de la fundación en las novelas del boom es que proyecta un modelo de la empresa histórica que se limita a la vida biológica de un hombre (la designación masculina por la especie también viene a ser significativa en este sentido). El novelista propone rescatar del olvido no a personas concretas sino a energías, deseos y sueños barridos en las contracorrientes de la historia. Pero son energías, deseos, sueños que todavía crecen en el individuo. En este sentido, aunque no son coextensivos con la ideología, una ideología de la empresa humana se pone en juego en estas novelas. Hay, además, contradicciones ideológicas que surgen cuando se hace del individuo la fuente de toda empresa o creación. En La casa verde, por ejemplo, la identidad individual está socavada por los cambios y las migraciones repentinas de los personajes que les hacen tomar nuevos roles o posiciones-efecto necesario al propósito "totalizador" de la narración. Sin embargo, la empresa en sí sólo puede ser narrada como individual. Donde, en estas novelas, se trata de una comunidad fundada "fuera" del sistema, como es el caso de Macondo o de la isla de Fushía, es una comunidad "procreada" como una empresa individual masculina en que lo femenino y los antiguos modos de vida colectiva son menospreciados. Aparecen sólo fragmentos de estas formas de vida: el arpa de Anselmo en $L a$ casa verde, último lazo tenuo con la comunidad ancestral de que proviene; el puesto de enganche en El astillero, último recuerdo de la época del gaucho. En esta forma, la empresa individual-discontinua y fragmentaria en esencia--emerge del vacío creado por, a la vez, el fracaso del capitalismo dependiente neocolonial y la desaparición de comunidades pre-colombinas, rasgos de las cuales, sin embargo, persisten en la imaginación y cultura popular, enfrentados a un sentido de racionalidad modelado sobre la metrópolis colonizadora. A la vez, la misma idea de "personaje" parece desplomarse en tanto que el novelista trata de mantener cierto grado de verosimilitud en su representación de una sociedad dependiente, sujeta a una causalidad parcialmente exógena. 11 Lo que caracteriza a Larsen, Artemio Cruz y Fushía es una discontinuidad radical entre su presente y pasado, o aun más, una desintegración total de su personalidad. Esto se debe, en parte, a que el proyecto totalizador de la novela no puede circundar la historia de América Latina como un desarrollo continuo contenido en el microcosmos del personaje individual.

11. Para algunas reflexiones sobre el concepto de "personaje", véase a Noe Jitrik, "Jugar su papel dentro del sistema" Hispamérica (año 1, no. 1, julio 1972), pp. 17-29. 
Los personajes que representan la energía empresarial en estas novelas no tipifican a una burguesía nacional, como es el caso, por ejemplo, de los Buddenbrooks. Son Petrus y no Larsen, Reátegui y no Fushía quienes pertenecen al sistema. Larsen y Fushía sugieren una ausencia-la ausencia en la realidad histórica latinoamericana de una clase dominante dinámica y autodeterminadora. De allí que Carlos Fuentes acuse a la burguesía mejicana de ser "totalmente ajena a cualquier idea de grandeza histórica, desconoce las maneras de consagrarse publicamente y posee una buena conciencia infinita que le hace considerar sus pequeños valores como eternos y perfectos". ${ }^{12}$ Su personaje, Artemio Cruz, está dividido entre una energía autónoma que pudo haber llevado al desarrollo de una nación independiente y la debilidad de una burguesía dependiente que se ha acomodado con el sistema.

El "desacuerdo con el mundo" (en palabra de Vargas Llosa) del novelista parece ser así menos con la noción de la empresa individual en sí que con su frustración en una sociedad dependiente. Marginalizado por la historia, el novelista reta la universalidad de la ideología metropolitana, demostrando las instancias donde se quiebra. Sus personajes toman posesión de su destino sólo en el momento de la muerte, entre ruinas o en el vacío humano de la selva.

El novelista del boom, por lo tanto, se sitúa ante la puerta del olvido. Por algo escoge García Marquéz como epígrafe de su primera novela las palabras de Creón en Antigona cuando manda que Polinice sea enterrado sin ningún signo de luto o recuerdo que perpetúe su memoria. La inscripción que generaciones enteras no lograron hacer en el libro de la historia ya reaparece, no como crónica, sino como un sueño de autorealización que sólo puede tener lugar en el espacio de la obra de arte. Aquí, como en el "territorio despótico" de Deleuze y Guatarri, todo emana del cuerpo del autor y es sólo a él a quien pertenece la inmortalidad. La culminación de este ciclo de novelas no puede ser otra que Yo el Supremo de Roa Bastos, en donde diez años después de Cien años de soledad se perfila sardónicamente una versión de este "supremo yo". Haciendo eco del epígrafe de La hojarasca, el doctor Francia, que en vano ha aspirado a ser el "autor" de un nuevo tipo de Estado, declara que la putrefacción atacará no sólo los que están enterrados fuera de la ciudad, "sin una cruz o signo que perpetúe sus nombres", sino también a los que yacen "debajo de enormes montones de tierra o aquellos más necios todavía que ordenan la construcción de mausoleos piramidales en donde guardar su tesoro de carroña". La novela de Roa Bastos merece ser mencionada porque

12. Carlos Fuentes, "Radiografía de una década: 1953-63", en Tiempo mexicano (México: Joaquín Mortiz, 1971), pp. 78-9. 
cuestiona la analogia creador/fundador en que se basan las novelas que hemos comentado. Francia, aunque un "yo" supremo, nunca logra fundar un discurso propio; por lo tanto, el "yo" del dictator no encuentra coincidencia con el "él" de la historia. Comentando su propria novela, Roa Bastos describe al "Supremo" de esta manera: "busca y ensaya la instauración de la Escritura del Poder, desconfiando del poder de la escritura". Rebelándose contra la noción del autor en las novelas del boom, Roa Bastos crea un "compilador" que ya no aspira a ser creador único sino a usar lo ya creado o expresado, poniendo en cuestión de esta forma "el concepto de la propiedad individual de los bienes intelectuales $y$ artísticos". ${ }^{13}$

Yo el Supremo cierra un ciclo para comenzar otro. Pero no tipifica lo sucedido en el caso de los novelistas del boom. Escritores como Vargas Llosa, García Marquéz y Fuentes, que se habían preocupado por llegar a un público, pronto tuvieron que confrontar, en la década de los sesenta, una nueva cultura: la cultura de masas que se apropiaba los géneros y las formas de la narrativa tradicional-novela amorosa, gótica, detectivesca; teatro melodramático. Muchas novelas escritas a mediados de los años sesenta, por lo tanto, trataron de incorporar la cultura de masas como tema, generalmente en forma de una parodia de su lenguaje y géneros. Las novelas de Vicente Leñero, Manuel Puig, Cabrera Infante, pero también las obras posteriores de Fuentes y Vargas Llosa ejemplifican esta nueva estrategia.

\section{DE AUTOR A SUPERESTRELLA}

Los escritores europeos comenzaron a confrontar los problemas surgidos del desarrollo de una cultura de masas en el siglo XIX cuando la avantgarde en Francia se separó fastidiosamente de la literatura del mercado para parodiar sus productos. En Inglaterra, Hardy y Conrad, hacia 1890, ya luchaban contra el hecho de que la literatura popular se había apoderado del "plot" novelesco, estereotipando en el proceso al personaje e imitando la voz narrativa "impersonal" que había permitido a novelistas anteriores inmolarse en su propia creación. De aquí en adelante el autor serio tiene que ser también un autor ensimismado, cohibido: "the selfconscious narrator". En Ulysses de Joyce, su héroe Bloom solicita anuncios periodísticos para ganarse la vida, y su esposa, Molly, se pierisa una estrella en embrión. La ironía no está en que perpetúan el mito de Ulises sino en su

13. Para una discusión de esta novela en relación a otras dos novelas en que la imagen del dictador latinoamericano es la fuerza autoritaria, véase a Angel Rama, Los dictadores latinoamericanos (México: FCE, 1976). 
distanciamiento de éste. Sin embargo, la utilización del mito por Joyce es significativa, ya que es el mito anacrónico que pueda organizar en un nivel más alto el caos de impresiones triviales y respuestas automatizadas que componen la vida diaria en la época de cultura de masas. Como señala Fred Jameson, la cultura de masas se caracteriza por la repetición. El esfuerzo vanguardista de hacer algo nuevo, radicalmente original, es en realidad, según Jameson, "an effort to produce something which resists and breaks through the force of gravity of repetition as a universal feature of commodity equivalence". ${ }^{14}$ En contraste, el "texto" de cultura de masas, sea en forma de música, fotonovela o. película, es siempre una repetición, ya que no existe original ninguno.

Esta propuesta de una relación dialéctica entre la estrategia del vanguardismo y la cultura de masas moderna ayuda a situar a un escritor como Cortázar, cuya producción entera es una lucha contra los efectos ahogantes del gesto automatizado y la palabra banalizada. Sin embargo, de acuerdo con la línea que vamos trazando aquí, quiero considerar más bien las respuestas de escritores como Fuentes y Vargas Llosa (y marginalmente Manuel Puig) al problema de la cultura de masas-respuestas mucho más ambiguas que la de Cortázar. Tanto Fuentes como Vargas Llosa se remontan una y otra vez a un narrador ideal: Balzac para Fuentes, Flaubert para Vargas Llosa. Vargas Llosa, en particular, escribe de Flaubert:

Pienso que el trastorno que significó para la cultura en general y para la literatura en particular el nacimiento de la sociedad industrial, el desarrollo veloz de la alta y media burguesía, es tan importante para explicar el anacoretismo de Flaubert como su situación familiar. En todo caso, es evidente que las condiciones estaban dadas para que, a partir de esta actitud de desesperado individualismo ante la vocación, lúcidamente asumida como una ciudadela contra el mundo, surgiera una estética de la incomunicación o del suicidio de la novela... 15

Según Vargas Llosa, Flaubert soluciona su problema produciendo una novela a la vez crítica y popular: "Sin renunciar a su pesimismo y desesperación, convirtiéndoles más bien en materia y estímulo de su arte, y llevando el culto de lo estético a un límite de rigor así sobrehumano, Flaubert escribió una novela capaz de congeniar la originalidad y la comunicación, la sociabilidad y la calidad". Balzac ofrece una piedra de toque similar para Fuentes. Ante la experiencia de la cultura de masas,

14. Fredric Jameson, "Reification and Utopia in Mass Culture", The Social Text (Madison, Wisconsin, Winter 1979), pp. 130-148.

15. Mario Vargas Llosa, La orgia perpetua: Flaubert y "Madame Bovary" (Barcelona: Barral, 1975), pp. 272-3. 
Fuentes y Vargas Llosa reaccionan tratando de acomodar formas y estrategias tradicionales de la novela a la destitución del autor por la estrella. El atentado de Vargas Llosa es el menos acorazonado. En La tía Julia y el escribidor combina a un escritor joven, Mario-proyección del propio novelista-, con un "Balzac" de la telenovela, un escritor que pone el mapa de Lima sobre la pared para guiarle en su Comedie humaine contemporáneo. Pero en la telenovela no es el autor quien es idolizado por las masas, sino la estrella que encarna el papel principal; así la concepción de La tía Julia suena falsa desde el comienzo. La capacidad inventiva del "escribidor" es eventualmente derrotada por un sistema que es insaciable en su deseo por más y más material violento, necesario para dar nueva vida a la situación formulada y para producir un enigma melodramático lo suficientemente excitante como para asegurar que los oyentes sintonizen el próximo episodio. Para cumplir con esta necesidad, el "escribidor" abarca temas más y más peligrosos, desde el incesto al canibalismo; al fin reta el tabú supremo al confundir voluntariamente los personajes. Pero a pesar de esta transgresión constante de la moral establecida en la radionovela, el deseo de Mario de casarse con su tía encuentra las dificultades tradicionales. El melodrama de la radionovela no tiene efecto directo en la moral social. La parodia de La tía Julia cae fuera del blanco. En realidad, la integración del código de la narrativa tradicional en la radionovela serial, y especialmente el enigma (al final de un capítulo o opisodio), le permite precisamente tratar temas "tabúes" y a la vez diluir, contener y regularizar éstas. Lo que está en juego en la novela de Vargas Llosa es el problema de la creatividad en una época de cultura de masas; pero es una creatividad todavía concebida en términos de una profesión de autor balzaciano, ahora reproducida en forma paródica para las "masas".

En contraste, Carlos Fuentes tiene muy presente, desde el comienzo de los sesenta, la aparición de la estrella como una amenaza para el "autor" tradicional. Su Zona sagrada puede ser vista como una alegoría del efecto distorsionante del "estrellazo" sobre la profesión de autor. La estrella de cine, Claudia, exclama continuamente a su hijo (el narrador) "Yo duro"; él, por el contrario, no resiste al tiempo. Pero Claudia es, en realidad, otra versión del autor. Es a la vez Circe y Penélope; su hijo, el narrador "Mito", desea unirse con ella. Desde su "zona sagrada", el espacio del narrador, Mito contempla la siempre cambiante, siempre fija cara de la estrella: "la idea platónica del ser humano". Su historia es el atentado de poseer esta imagen como símbolo y fetiche a la vez. En uno de los capítulos finales, Mito se viste con la ropa de su madre, deseando ser ella, sólo para encontrar que esta pantomina lo ha convertido en un impostor, en un perro, dedicado a la destrucción de la "bruja". Como el troglodita en "El 
inmortal" de Borges, a quien el narrador da el nombre de Argos (el perro de Ulises), el perro/narrador de Zona sagrada es también una figura "homérica", siendo una reencarnación de Telémaco. La Claudia de Zona sagrada asegura haber sucedido a Pancho Villa como símbolo de México; sin embargo la fuerza alegórica de la confrontación entre estrella y narrador queda oscurecida en la novela por el juego de referencias mitológicas. El problema es que el mismo Fuentes se mantiene encerrado dentro de la esfera de la estrella ante la cual el narrador puede adoptar solo actitudes de contemplación, narcisismo y auto-inmolación.

Hay otro lazo importante con la cultura de masas. Si la época de reprodución mecánica de la cultura envuelve el fenómeno de la repetición es porque tanto la memoria como la historia ya no sirven como índices del destino público o individuo. La repetición impone un patrón o hábito en la mente del consumidor, facilitando así su absorbción de material nuevo y reintegrando su impulso original al consumo. La repetición en la sociedad moderna sirve para conducir a deseos y necesidades dentro de los confines estrechos de las relaciones capitalistas, y por lo tanto, para reprimirlos. En este sentido es fundamentalmente diferente del ritual en sociedades tradicionales, cuya función, según Levi-Strauss, es "conjugar", unir. La repetición en la cultura de masas (especialmente en el caso de oír la radio o mirar la televisión solitariamente) se dirige a un individuo aislado y agudiza su aislamiento al unir especularmente sus deseos íntimos a la imagen en la pantalla o al objeto de gusto. Lo que Fuentes trata de hacer en Zona sagrada es rescatar la repetición como la única forma de inmortalidad que ofrece la cultura de masas y elevarla al plano de un "mito" en que Claudia y su hijo toman respectivamente los roles de Penélope/Telémaco, Circe/las bestias, etc. Mientras una estética vanguardista como la de Cortázar trata de producir un efecto de desautomatización, negando así la repetición, Fuentes trata de sublimarla.

Esta ambigüedad fundamental ante la cultura de masas puede ser ejemplificada en una novela un poco más compleja, Cambio de piel. Su narrador, Freddy Lambert-"portador de la palabra posible y los personajes portadores de las palabras devenido imposible" 16 -no es sino un anacronismo tomado de una versión anterior de la novela, El sueño. Fue sólo en forma de una reflexión posterior también que al mismo Fuentes se le ocurrió incorporar a Cambio de piel dentro del marco de las teorías de McLuhan. "Hay algo más en Cambio de piel, algo que sólo ahora entiendo, al leer a Marshall McLuhan, y es una cierta participación en el nuevo mundo circular, o de integraciones simultáneas y explosivas

16. Entrevista a Fuentes por Alberto Díaz Lastra, "La cultura en México", Siempre 718 (29 de marzo, 1967). 
que ha venido a sustituir al mundo lineal, individual, del punto de vista y las motivaciones". ${ }^{17} \mathrm{El}$ "global village" de McLuhan requiere un nuevo tipo de narrador y un nuevo tipo de novela, el cual, como señala Fuentes en otra ocasión, requiere también el sacrificio del mismo novelista. Ya que es imposible la novela burguesa "de" México (porque la visión totalizadora no puede incluir todas las imágenes de una cultura de masas multinacional y porque la época de la tecnología reconoce la estrella en vez del héroe, la repetición en vez de la historia), la vieja forma de la novela-su "piel"-es reemplazada por el "happening". Los Beatles, en vez de Balzac, vienen a ser el modelo cultural. La novela que Fuentes concibió alrededor de 1965 como El sueño incluía todavía personajes "existenciales" con memorias propias o historias de familia. Sólo en en transcurso de su escritura vinieron a parecer estas historias anacrónicas, porque como explica el autor:

...vivimos en sociedades modernas maltratadas, inundadas de objetos, de mitos y aspiraciones de plástico, aluminio, y tenemos que encontrar los procedimientos, las respuestas, al nivel de esa realidad; tenemos que encontrar las nuevas tensiones, los nuevos símbolos, la nueva imaginación, a partir del Chicle Wrigleys y la telenovela y el frug y el bolero y Los muchachos de antes no usaban gomina. Antes que en la cultura, el mexicano o el bonaerense o el limeño actuales somos contemporáneos de todos los hombres en la mercancía y las modas. (subrayado mío) 18.

Esto explica porque Fuentes, a la vez que logra captar algunos aspectos de la "sociedad del espectáculo", también sucumbe a la atracción de su universalismo estelar. Explica porque en Cambio de piel se sobrepone a una novela original de inspiración existencialista una alegoría de su propia destrucción. Explica también su empleo un tanto gratuito de fotografíasdel pequeño niño judío rodeado por la nazis en Varsovia, del gabinete del doctor Caligari, de estrellas del cine de los años treinta. De paso, podemos anotar, además, cómo el mismo Fuentes se hace fotografiar con estrellas del cine y cómo le gusta dedicarles sus libros. ${ }^{19}$ Debemos, sin embargo, preguntarnos por qué están estas fotografías en Cambio de piel: ison simplemente un gesto a una imagen mecánica cuya importancia él recoge sin saber cómo incorporarla a la ficción? Hay algo más: al final de la

17. Entrevista de Díaz Lastra.

18. Entrevista por Emir Rodríguez Monegal en el Homenaje a Carlos Fuentes, Helmy F. Giacoman (ed.) (N.Y: Las América, 1971), pp. 47-8.

19. Esto se lleva a los extremos en la entrevista llevada a cabo por James R. Fortson en Perspectivas mexicanas desde París (México: Corporación Editorial, 1973). Esta entrevista fue publicada por primera vez en la revista mexicana $E l$ (sucursal de la revista Playboy) haciendo de Mario Vargas Llosa un "male pin-up" e incluyendo una sección titulada "Kant y los detergentes". 
novela, después del derrumbe de la pirámide de Cholula, que aplasta a los personajes más viejos y deja al narrador entre el grupo carnavelesco de los monjes, éste revela los contenidos de su baúl, que incluye una serie de fotografías de todos los lugares visitados por los personajes de la novela. Incluye también una serie de películas viejas: El Golem, Nosferatu, El angel azul, Vampyr, Das Rheingold y Caligari-precisamente las películas mencionadas en el libro de Kracauer, De Caligari a Hitler, que estudia la relación entre la película y el totalitarismo. El narrador de Cambio de piel se llama Freddy Lambert y al final se encuentra, como Caligari, en un manicomio. El lector, sin embargo, tendrá poca dificultad en reconocerle como una reencarnación tardía del personaje balzaciano Lucien Lambert, que se volvió loco después de hundirse en filosofías de lo "irracional". Se espera, por lo tanto, que el lector aprecie también lo "irracional", representado por una cultura de la juventud ("youth culture")-el "happening", el erotismo sin culpabilidad contrapuesto a la misión racionalizadora de la sociedad moderna que contamina, todo de la vieja generación en la novela. Porque el "cambio de piel" del título describe no sólo el asunto de la novela, sino un cambio radical en la visión que tiene Fuentes de la literatura; su última parte tiene un carácter ajeno, como si perteneciera a otra obra. El derrumbe de la pirámide que aplasta a algunos de los personajes también representa una quiebra, con características tradicionales de la novela - el "plot" que tiene la forma de un viaje, los personajes cuyo presente está dominado por su pasado-, una quiebra que libera nuevas energías del mismo acto de destrucción. Pero Fuentes sólo refleja, en vez de sublevarse contra lo que pasa en una sociedad corporativa: la pseudo-liberación del sujeto de su pasado está destinado a organizar sus energías y deseos más eficazmente alrededor del consumo. En todas las novelas tardías de Fuentes-Cambio de piel, Terra Nostra y La cabeza de la hidra-aparece un autor/narrador loco, marginado y/o transformado. En La cabeza de la hidra el personaje central manipulado viene a ser Diego Velázquez, y éste un personaje creado por Timón de Atenas. Parecería que Fuentes puede concebir al autor en la sociedad moderna sólo identificándole con una figura anacrónica o con manipuladores de la realidad.

Aparte de esta respuesta de mandarin-el esfuerzo de abstraer la novela por completo del mundo en una reacción similar a la "poesía pura" de una generación anterior-, la época de cultura de masas admite sólo o una amalgama híbrida de formas anteriores de la narración (historia oral, biografía) o la parodia. Cabe mencionar, sin embargo, las posibilidades creadas por otros dos escritores-Cortázar y Puig-que pretenden estetizar al objeto de consumo de la cultura de masas. 
Tomemos primero brevemente el caso de Cortázar. En su nouvelle clave, El perseguidor, presenciamos una transferencia de la noción de creatividad del narrador al artista de jazz; modelado sobre la figura de Charlie Parker. La experiencia del jazz solo viene a ser una manera de manifestar la unificación utópica de elementos que siempre han sido separados en la cultura burguesa: artista y espectador, autor y lector, cultura dominante y culturas dominadas. Para Cortázar los objetos pre-fabricados (ready-made) y los productos de la cultura de masas siempre pueden ser modificados - "enajenados"- de tal forma que pierden su carácter de mercancía. Con la radicalización de Cortázar en los sesenta, su esfuerzo de estetificación se extiende no sólo al arte sino a la política. Sin embargo, a pesar de su politización de la estética de vanguardia, la confrontación de Cortázar con la cultura de masas es solamente con formas ya superadas en cierto sentido. Por ejemplo, escoge a Fantomas, un héroe ya consagrado por los surrealistas, para combatir a los "vampiros" multinacionales; no podría hacer lo mismo con una figura más del momento actual como James Bond. Fantomas tiene como subtítulo Una utopia realizable; nos presenta en forma de un comic strip una conspiración de la CIA para destruir las bibliotecas del mundo. Entran en la acción, por lo tanto, los "autores," con nombres como Octavio Paz, Alberto Moravia, Susan Sontag, etc. Como héroe de una época individualista, Fantomas por sí mismo ya no sirve para derrotar a las corporaciones multinacionales; necesita la ayuda tanto de los escritores como de las masas, cuyas miles de voces comunican su adhesión a la causa humana. Aquí lo utópico consiste precisamente de esta comunicación ideal entre Fantomas, los escritores y las masas anónimas. Sin embargo, los primeros tienen nombre propio, mientras que las masas son representadas sólo como acentos - "una voz argentina". De esta forma, se perpetúa la jerarquía de élite/masa creada y reproducida por los efectos de la cultura de masas.

Todos estos autores generan una dimensión alegórica, ya duplicando la situación de autor en sus personajes, ya como en el caso de Fuentes y Cortazar, haciendo un juego de diferencia e identidad entre las figuras del narrador y la estrella. La originalidad de Puig en La traición de Rita Hayworth es que, aprovechándose de esta dimensión alegórica, logra captar directamente la serialidad de la cultura de masas, su efecto de hablar a cada persona por separado y no en grupo. Su narración es una compilación de discursos hablados o escritos- monólogos interiores, cartas, diarios, memorabilia, conversaciones, ejercicios de escuela. El cine (como la religión) no sólo provee ideas de lo bueno/malo, bello/feo, correcto/incorrecto; también sirve a los personajes de la novela como un punto común de referencia, por ejemplo, entre Toto y sus padres. De esta 
forma el cine comienza a desplazar la función de la religión. La estrella del cine deviene una especie de tipo ideal del cual el niño Toto deriva sus ideas de lo mortal y lo inmortal, la mujer, su idea del hombre deseable, el hombre, su idea de la mujer deseable. Así se va creando un nuevo folklore que afecta al lenguaje, los patrones de conducta y las creencias. Todo esto está puesto en escena en un pueblo de provincia en los años entre 1933 y la dictadura de Perón-período en que el glamour de Eva Perón fue una forma de manipulación política. Evita llega a ser un tipo ideal no sólo porque poseía lo deseado-la belleza, la riqueza, el poder-sino también como símbolo de la generosidad, de lo que se ofrece al espectador/consumidor pasivo. En La traición el tema del peronismo en sí es secundario. El momento histórico narrado, sin embargo, es importante en la historia del cine argentino; abarca los años de la Segunda Guerra Mundial, cuando Nelson Rockefeller saboteó eficazmente la industrial nacional del cine privándola del celuloide. De allí que sea el cine de Hollywood el que servirá a los sueños de Toto y su madre, un cine transnacional, en el que predomina el espectáculo. El racismo, el esnobismo, el machismo cotidiano, la dependencia, indican la insuficiencia y miseria de la vida, que el cine anega, no en la acción, sino en la contemplación narcisista.

A diferencia de la estrategia vanguardista de recuperar al lenguaje y las formas del proceso de automatización generado por la cultura de masas, La traición de Rita Hayworth "estetifica" lo banal, ennobleciéndolo de cierta nostalgia, convirtiéndolo en objeto de contemplación. La novela, en este sentido, permanece dentro de los límites de la conciencia de la clase que describe, esa pequeña burguesía latinoamericana fragmentada por el desarrollo capitalista, cuyas esperanzas se reducen al mejoramiento individual y a la integración social.

\section{CONCLUSIONES}

Lo que hemos bosquejado aquí no es una historia o un desarrollo, sino un momento de transición. Antes de los años cincuenta, la presentación idealizadora de un héroe intelectual capaz de dominar una realidad bruta era común en la novela latinoamericana. En las novelas del boom que he mencionado, sin embargo, el novelista y el supuesto narrador se separan de la empresa social representada, cuya frustración y fracaso se contraponen al éxito del novelista como autor de un texto/espacio "original", creador de una "realidad alterna". El final de Los pasos perdidos-cuando el narrador abandona su esfuerzo de redescubrir la colonia en la selva-alegoriza claramente esta separación, separación que permite al artista salirse de los anacronismos a que la situación de su país ha sido sujeta. Por una 
serie de razones muy complejas relacionadas con la desintegración de ciertos recursos tradicionales de la novela como el concepto de personaje; con el nuevo énfasis en la creatividad del lector; y con la destrucción de formas sociales hasta entonces perdurables en América Latina, el proyecto totalizador de construir esta "realidad alterna" se vuelve problemático o imposible a finales de los años sesenta. Los novelistas no sólo tienen que confrontar una cultura masificada y multinacional que destruye cualquier noción tradicional de cultura nacional, sino que muchas veces se encuentran ellos mismos convertidos en estrellas por los medios masivos de comunicación. Por lo tanto, el efecto de esta situación se ve no sólo en los esfuerzos de los escritores establecidos de la vanguardia para producir un texto "inconsumible", sino también en el encuentro de los escritores del boom con la fascinación iresistible de la estrella y la imagen. Lo cual sucede con la novela en una época en la que la imagen viene a ser el portador de la ideología y el significado todavía no es del todo evidente. 